\title{
Response control of structures under Seismic and Blast induced ground motions
}

\author{
Siripuram Vamshisheela ${ }^{1}$, Atulkumar Manchalwar ${ }^{2}$ \\ ${ }^{1} \mathrm{M}$. Tech Student, Gokaraju Rangaraju Institute of Engineering and Technology, Hyderabad, India \\ ${ }^{2}$ Assistant Professor, Gokaraju Rangaraju Institute of Engineering and Technology, Hyderabad, India
}

\begin{abstract}
In the present paper an investigation is carried out to evaluate the efficiency of Base Isolation device in a building subjected to both seismic and blast induced ground motions. A 5- story building is modelled with different story stiffness and floor masses is considered in this study. In SAP 2000 software two buildings, one with fixed base and the other with isolated base are designed and nonlinear time history analysis is conducted. The structural responses of these two models subjected to four recorded earthquakes and four different blast ground accelerations is compared in this study. The base isolated device such as lead/rubber bearing have proved to be effective in reducing the base Shear and Top story acceleration, and also increase in Hysteresis energy in the base isolated structure subjected to seismic and blast vibrations.
\end{abstract}

\section{Introduction}

Earthquake and Blasts cause catastrophic destruction to the mankind, environment and structural assets. Blast is a high intensity Earthquake of shorter duration, whereas Earthquakes are of low intensity with longer duration. Due to Blasts the building is loaded globally and cause damage to the building façade, and due to an Earthquake building is loaded locally. Blasts and seismic vibrations are two different scenarios, so the response of the structure need to be studied. Earthquake engineering is a well-researched area; Therefore, this paper mainly targets to control the responses and its effects on the structure under blasting and seismic forces.

In this study, the effectiveness of supplemental passive control technique such as Base Isolating devices are used to protect building from seismic and blast loads and the improvement of Structural response from Blast and Seismic loads that Base Isolation provides has been focussed in this study. Ranjan kumar et al., (2016) has proposed PPV empirical formulae by collecting a total of 1089 published blast data. To reduce the effect of vibration on the rock fragments which is induced by a blast, a correlation has been developed which was proposed by Cardu et al., (2019). Mondal et al., (2016) carried out comparative studied on the effectiveness of different isolation systems such as friction and elastomeric based systems.

In addition to above mentioned studies Kangda and Bakre (2017) carried out an investigation to know the LRB's performance to minimise the structural responses of a five-story model subjected to earthquake and blast loading. In another study in (2018), they have employed base isolator with FVD in combination on a 10- story regular RC Structure under vibrations of blast and
Earthquake. Later, Kangda and Bakre in (2018) developed blast load time histories based on previous research work and demonstrated the effectiveness of BI technique such as LRB in minimisation of structural responses under blast loading. The behaviour of HTSRD (High Toughness Steel Ring Dampers) along with NRB (Natural Rubber Bearing) combined with weld for various arrangements is presented by Javad et al., in (2020).

Mondal et al., (2014) investigated that by the use of Fluid Viscous Damper, the structural vibrations have been reduced in the structure due to blasting. Aria Ghabussi et al., (2019) focussed to evaluate the performance of SCD i.e., Steel Curve Damper for various angles (30, 60, 75, 90 \& 120 degrees), dimensions and materials of portal frame. Deringol and Husseyin Bligin (2018) examines the effect on structure when steel frames isolated by LRB and also effectiveness of Base Isolators.

In this study, the behaviour of five story building subjected to both Earthquakes and Blast forces is studied for the building without isolator and with isolator.

\subsection{BI protection from Earthquake and Blast Ground Accelerations}

$\mathrm{BI}$ technique isolates the structure from ground which is rested on flexible pads that offer opposes lateral movement, and shifts the natural period thus ultimately resulting in decrease of natural frequency of the building by changing the mode shape. The shift in this period results in dissipation of maximum amount of energy thus increasing the energy absorbing capacity of the isolator. 


\section{Blast Excitations}

Hinman, Carvalho and Battista have calculated the accelerations of blasts for different charge weights $\ddot{x} g(t)$ which is an exponential decay function given as follows

$\ddot{x} g(t)=-\frac{1}{t d} v e^{\frac{-1}{t d}}$

In the above equation, td is the time for arrival which is evaluated using the formula $t d=R / C$, here $\mathrm{R}$ is the distance from the point of charge $(\mathrm{m})$ and $\mathrm{C}$ is velocity of propagated wave $(\mathrm{m} / \mathrm{s})$. $\mathrm{V}$ is the maximum velocity of a particle, these empirical formulae to calculate ' $\mathrm{V}$ ' is proposed by Kumar et al., derived from field data available for different cases is given as

$v=\frac{f^{0.642} S D^{-1.463}}{\gamma D}$

Where, $\mathrm{f}$ is uniaxial compressive strength of granite rock deposit and taken as $\mathrm{f}=70 \times 10^{6} \mathrm{~Pa}, \mathrm{SD}$ (Scaled Distance) which is given as $R / \sqrt{Q}, \mathrm{R}$ is the mass of charge. The charge weight $\mathrm{Q}$ in present study is taken as $10 \times 10^{3} \mathrm{~kg}$, $25 \times 10^{3} \mathrm{~kg}, 50 \times 10^{3} \mathrm{~kg}$ and $75 \times 10^{3} \mathrm{~kg}$.

$\gamma D$ is the average mass density taken as $26.50 \times 10^{3}$ $\mathrm{KN} / \mathrm{m} 3$ and young's modulus $\mathrm{E}=73900 \mathrm{MPa}$, which depends on the material properties of granite.

\section{Building Model}

For the numerical analysis, the acceleration data include most commonly cited four different Earthquake records (Kern County Earthquake, Loma Prieta -Oakland Outer Harbour Wharf, San Fernando Earthquake, Parkfield Earthquake) Which were taken from FEMA P-695.

In the present study, a simple low-rise building, a fivestory isolated structure. The model is lumped mass system. The variables of the system are listed in the table. Under all external dynamic excitations, the model is assumed to be remained linearly elastic which facilitates with a scenario where non-structural components may be damaged and non-structural components remain functional.

This structure is modelled using Sap 2000 software for isolated base and another for fixed. The natural period of the building with which base is fixed is $0.54 \mathrm{sec}$ whereas, for the base isolated model the fundamental natural period is $2.5 \mathrm{sec}$.

By supplementing the building with base-isolation device, there is a shift in the natural period of the building such that maximum amount of energy is dissipated during an earthquake and blast vibrations.

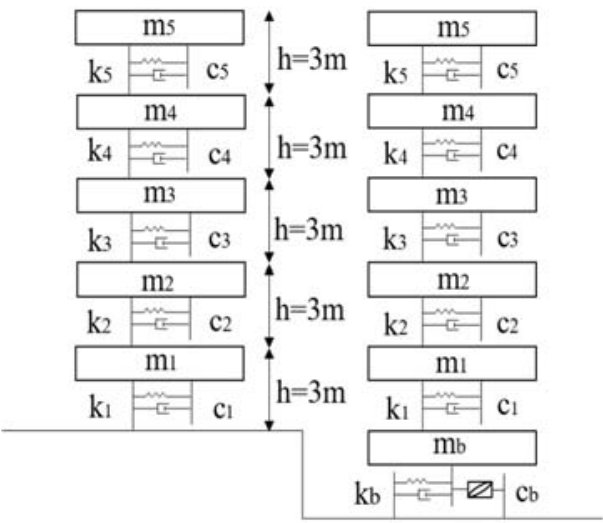

Fig. 1. Diagrammatic representation of five story model

Table 1. Variables of five story building models.

\begin{tabular}{|c|c|c|c|}
\hline STORIES & $\begin{array}{c}\text { MASS } \\
\text { ON } \\
\text { FLOOR } \\
\text { M } \\
\text { (tons) } \\
\end{array}$ & $\begin{array}{c}\text { STORY'S } \\
\text { STIFFNESS } \\
\text { K } \\
(\mathbf{N} / \mathbf{m})\end{array}$ & $\begin{array}{c}\text { DAMPING } \\
\text { COEFFICIENT } \\
\text { C } \\
(\mathrm{kg} / \mathrm{s})\end{array}$ \\
\hline Floor 1 & $\begin{array}{c}\mathrm{m}_{1}= \\
53.073\end{array}$ & $\begin{array}{l}\mathrm{k}_{1} \\
=101196 \times 10^{3}\end{array}$ & $\mathrm{c}_{1}=348.14 \times 10^{3}$ \\
\hline Floor 2 & $\begin{array}{c}\mathrm{m}_{2}= \\
53.073\end{array}$ & $\begin{array}{l}\mathrm{k}_{2}=87279 \\
\mathrm{x} 10^{3}\end{array}$ & $\mathrm{c}_{2}=301.38 \times 10^{3}$ \\
\hline Floor 3 & $\begin{array}{c}\mathrm{m}_{3}= \\
53.073\end{array}$ & $\begin{array}{l}\mathrm{k}_{3}=85863 \\
\mathrm{x} 10^{3}\end{array}$ & $c_{3}=296.18 \times 10^{3}$ \\
\hline Floor 4 & $\begin{array}{c}\mathrm{m}_{4}= \\
53.073\end{array}$ & $\begin{array}{l}\mathrm{k}_{4}=74862 \\
\mathrm{x} 10^{3}\end{array}$ & $\mathrm{c}_{4}=259.81 \times 10^{3}$ \\
\hline Floor 5 & $\begin{array}{c}\mathrm{m}_{5}= \\
53.073\end{array}$ & $\begin{array}{l}\mathrm{k}_{5}=57177 \\
\mathrm{x} 10^{3}\end{array}$ & $c_{5}=197.45 \times 10^{3}$ \\
\hline
\end{tabular}

The Isolator parameters such as initial stiffness, post yield stiffness is calculated by standard formulae of Time period i.e., $\mathrm{T} b=2 \pi \sqrt{\frac{M}{K}}$ mand post yied stiffness ratio $\alpha=\frac{k p}{k i}$ where, $\alpha$ is taken as 0.1 and $\mathrm{Tb}$ is taken as 2 , 2.5 and $3 \mathrm{sec}$. Yield strength of the isolated is given by equating the ratio of $\frac{Q}{W}$ to $0.05,0.075$ and 0.1 Here, $W$ is the total weight of structure.

\subsection{Base shear comparison}

To assess the performance of LRB, nonlinear dynamic analysis such as time history analysis is conducted and time history graphs are plotted between base shear $(\mathrm{KN}) \mathrm{vs}$ time (sec). These graphs were plotted for 4 different seismic ground motions and 4 different blast ground accelerations. The following graphs shows that the base shear is controlled in a very large scale when the building is isolated compared to building without isolator. 


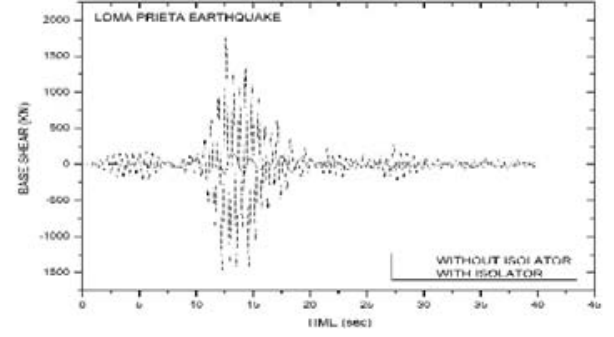

2(a)

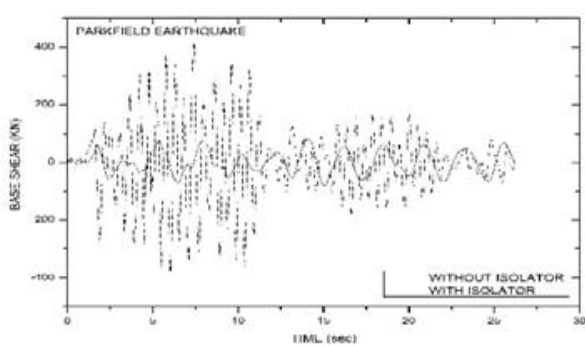

2(b)

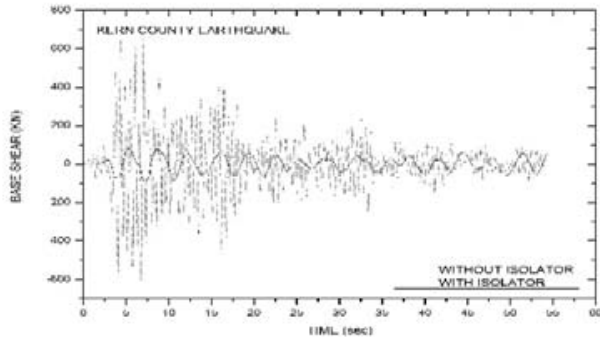

2(c)

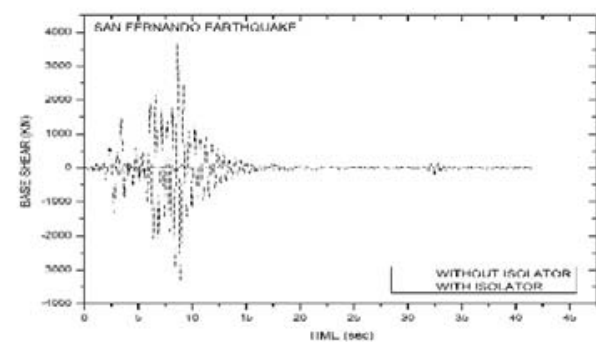

2(d)

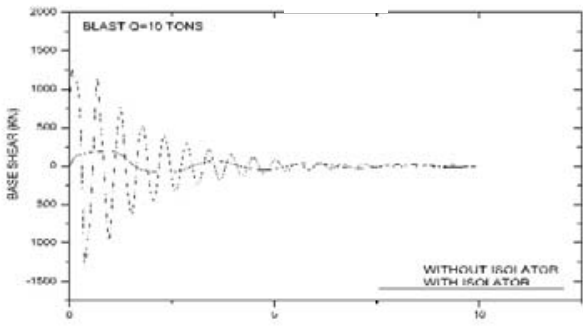

2(e)

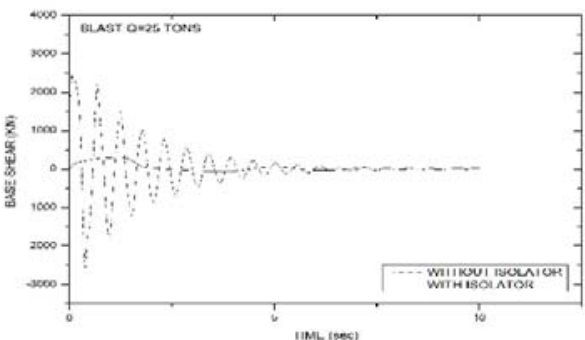

(f)

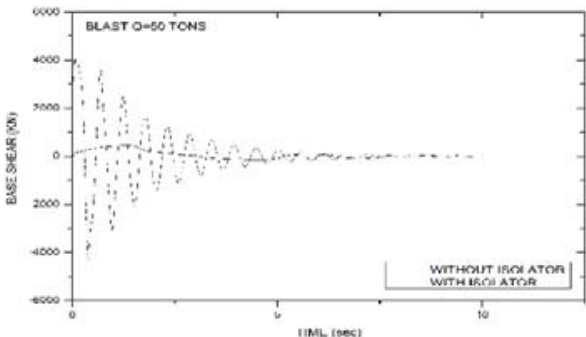

$2(\mathrm{~g})$

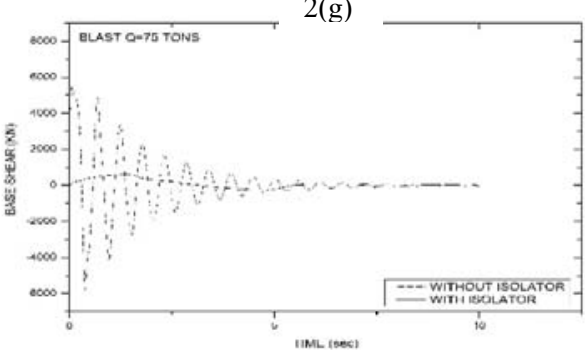

2(h)

\subsection{Acceleration comparison}

A particular characteristic of floor acceleration is that they increase along the building height, with a maximum amplification of the roof top level. When building is subjected to dynamic excitation, the responses through the analysis were drawn from the time history graphs which were plotted between top story acceleration $\left(\mathrm{m} / \mathrm{sec}^{2}\right)$ vs time $(\mathrm{sec})$. The following graphs shows the amount of reduction in top storey acceleration for the building which is isolated for 4 seismic and 4 blast induced ground motions.

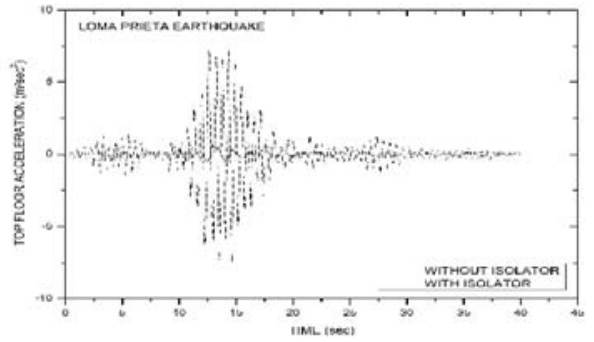

3(a) 


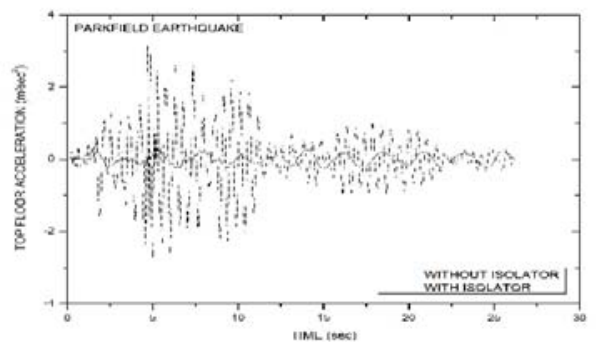

$3(b)$

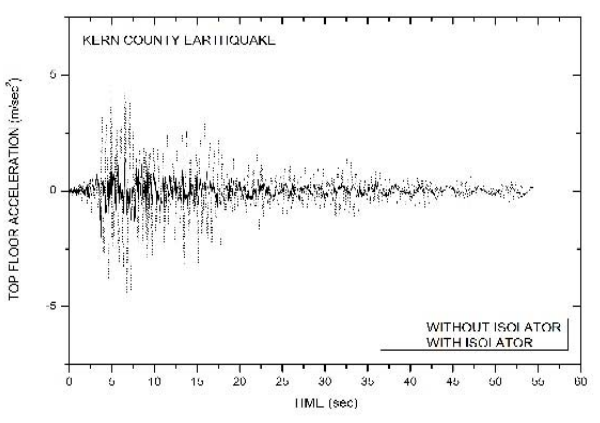

3(c)

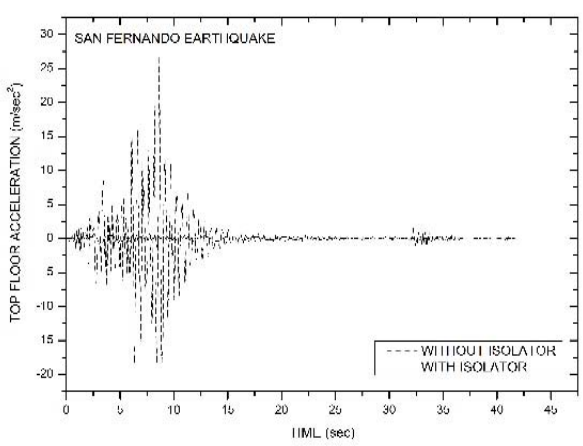

3(d)

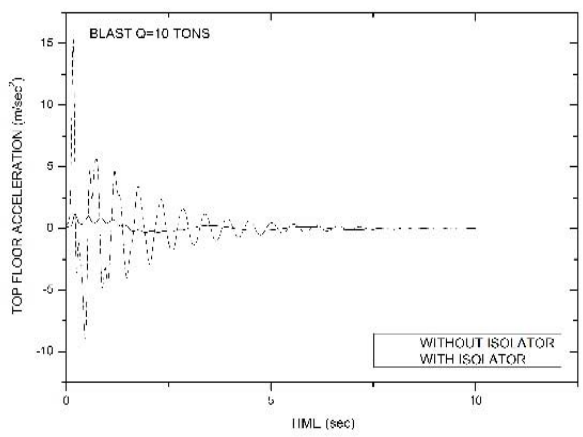

$3(\mathrm{e})$

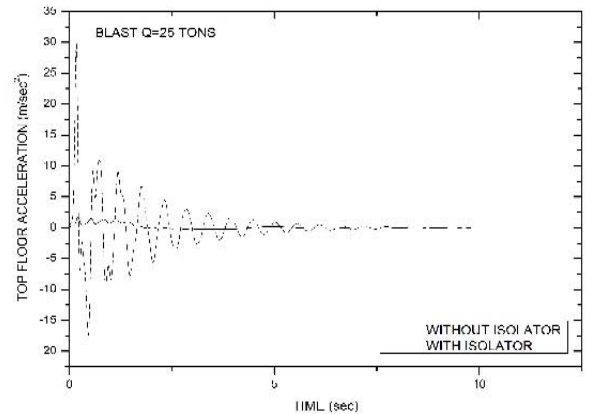

$3(\mathrm{f})$

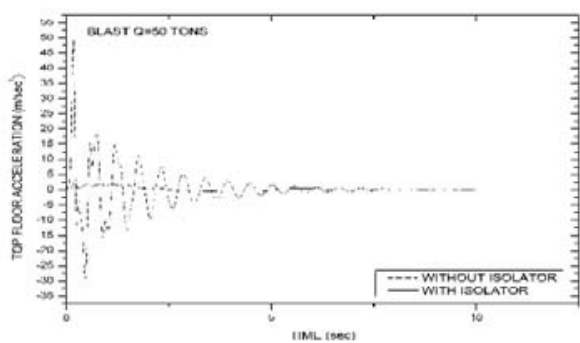

$3(\mathrm{~g})$

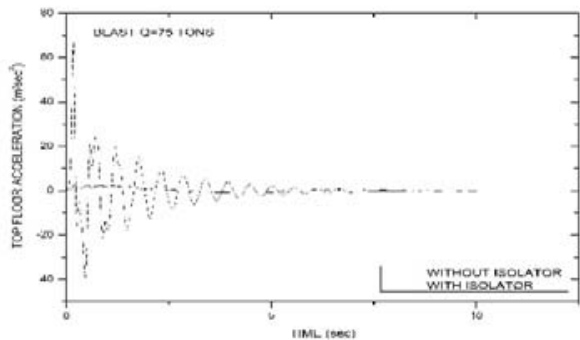

3(h)

Fig. 3

\subsection{Hysteresis energy}

As Earthquake and Blast produce high amount of energy which is destructive in nature, this energy has to be controlled. Controlling this amount of energy controls the structural behaviour. The amount of hysteresis energy in a structure could be an index of its level of damage in structure. The following graphs are time history graphs plotted between Force (KN) vs Deformation (m)for 4 seismic and 4 blast induced ground motions. These graphs shows that the building with LRB has subjected to less deformation. 


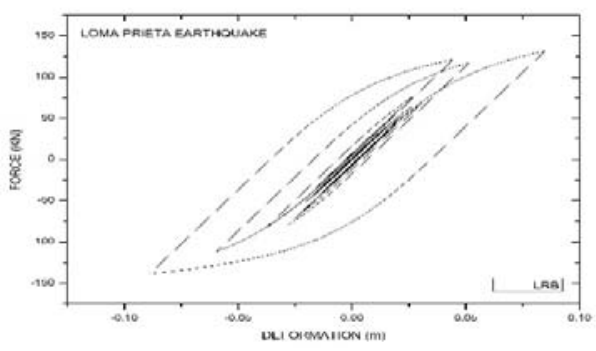

$4(c)$

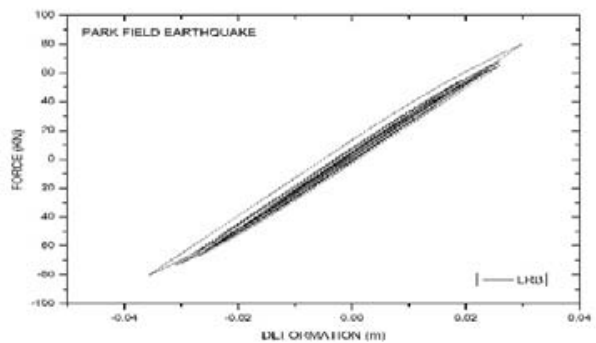

4(d)
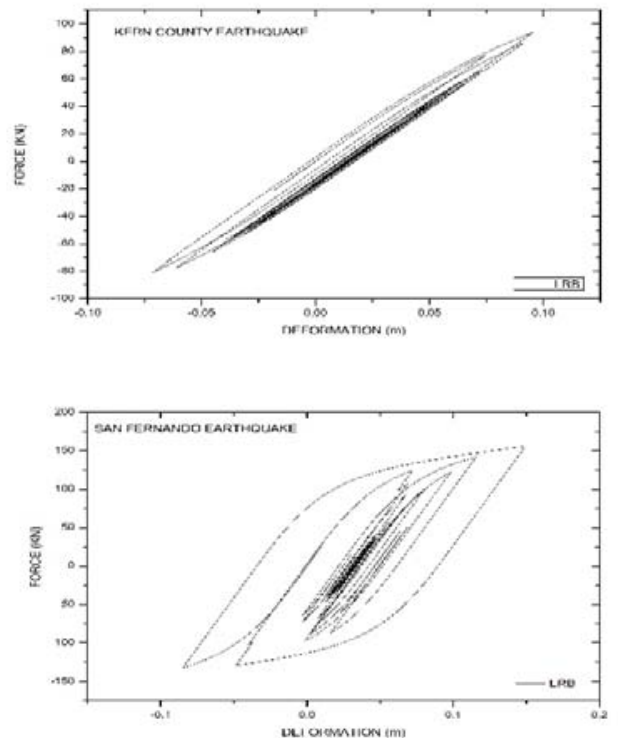

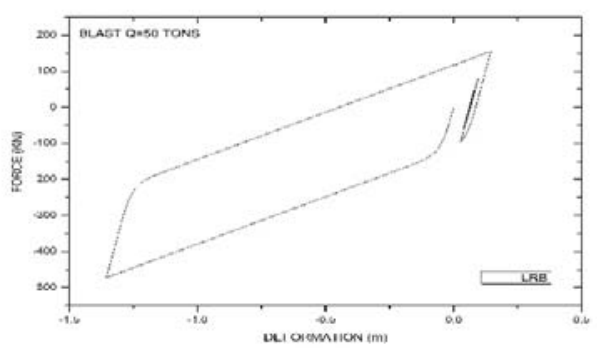

$4(\mathrm{e})$

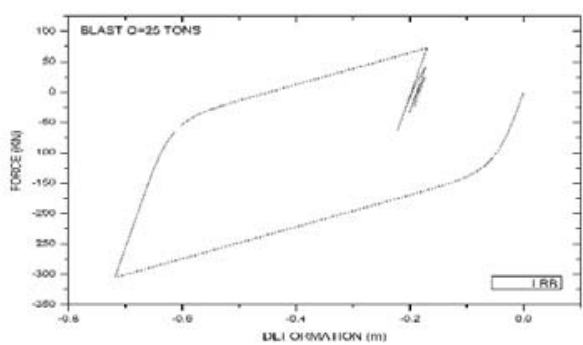

4(f)

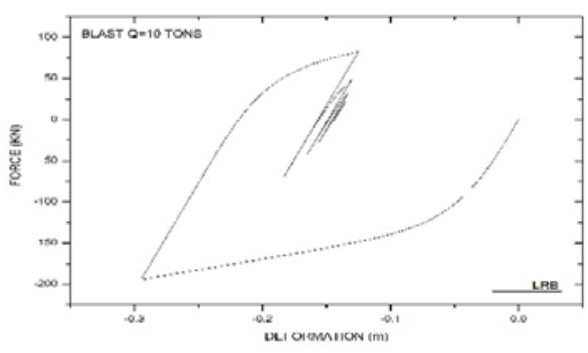

$4(\mathrm{~g})$

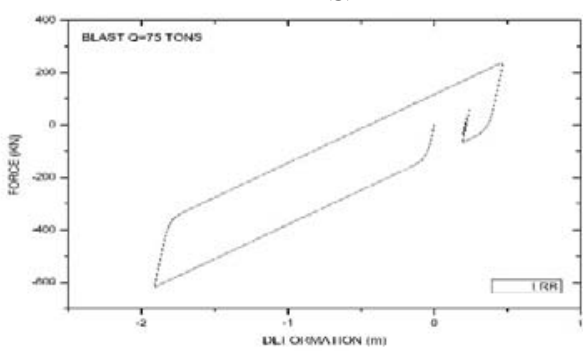

4(h)

Fig. 4

\section{Conclusion}

This study concludes that the BI device LRB is supplemented to a five-story building under seismic and blast accelerations. The blast accelerations were driven from an exponential decaying function in the form of ground accelerations, and the seismic records were taken from FEMA P-695. To evaluate the performance of LRB, a non-linear dynamic analysis is carried out using SAP 2000 software. By the use of LRB, there is reduction in base shear, top story acceleration and building is subjected to less deformation when the building is under dynamic excitations which is shown in the form of graphs. Therefore, from this paper it is 
understood that BI devices are effective in controlling the structural responses of the structure.

\section{References}

1. Kumar, Ranjan, Deepankar Choudhury, and Kapilesh Bhargava, J. of Ro. Mech. and GT Engineering 8.3, 341-349 (2016).

2. Cardu, Marilena, Dario Coragliotto, and Pierpaolo Oreste, IJMST 29.6, 905-915 (2019).

3. Mondal, Papiya D., Aparna D. Ghosh, and Subrata Chakraborty, IJSSD 17.04, 1750043 (2017).

4. Kangda, Muhammed Zain, and Sachin Bakre, Arab. Jou. for Sci. and Eng. 43.4, 1761-1776 (2018).

5. Kangda, Muhammed Zain, and Sachin Bakre, Jou. of Vib. Eng. \& Tech. 8.1, 1-26 (2020)

6. Kangda, Muhammed Zain, and Sachin Bakre, Arab. Jou. for Sci. and Eng. 44.5, 4971-4992, (2019)

7. Sheikhi, Javad, Mojtaba Fathi, and Rohola Rahnavard, Structures. Vol. 24. Elsevier, (2020)

8. Mondal, Papiya D., Aparna Ghosh, and Subrata Chakraborty, IJMSI 8.4, 273-290 (2014)

9. Moradpour, S., and M. Dehestani, Structures. Vol. 22. Elsevier, (2019)

10. Ghabussi, Aria, Jafar Asgari Marnani, and Mohammad Sadegh Rohanimanesh. Structures. Vol. 24. Elsevier, (2020)

11. Zhang, Ruiyang, and Brian M. Phillips, Journal of Eng. Mech. 142.1,04015063 (2016)

12. Sravya, G. Jyothi Sri, and Atulkumar Manchalwar, IJRTE 12336-12339.

13. Carvalho EM, Battista RC, Proc. Inst. Civ. Eng. Struct. Build. 156(3), 243-253 (2003)

14. Kumar R, Choudhury D, Bhargava K, J Rock Mech. Geotech. Eng. 8(3), 341-349 (2016)

15. Jangid RS, Kelly JM, Earthq. Eng. Struct. Dyn. 30(5), 691-707 (2001)

16. Reddy, N. Omprakash, and A. Manchalwar. E3S Web of Conf. Vol. 184. EDP Sciences (2020)

17. Manchalwar, Atulkumar, and S. V. Bakre. IJDC 1-10 (2020)

18. Manchalwar, A., and S. V. Bakre, Soil Mech. and Foun. Engi. 57.2, 170-177 (2020)

19. Manchalwar, Atulkumar, and S. V. Bakre. Jour. of Vib. Engi. \& Tech. 7.3, 261-275 (2019)

20. Manchalwar, Atulkumar, and Sachin V. Bakre, Proc. of the Insti. of Civ. Engi. Stru. and Buil. 172.11, 836-856 (2019)

21. Sravya, G. Jyothi, and A. Manchalwar. E3S Web of Conf. Vol. 184. EDP Sciences, (2020)

22. Manchalwar, A., and S. V. Bakre, Jour. of The Inst. of Engi. (India): Series A 97.4, 415-425 (2016)

23. Nirmala, G., and Atulkumar Manchalwar, E3S Web of Conf. Vol. 184, EDP Sciences, (2020)
24. Kumar, P., Singhal, A., Mehta, S., Mittal, A, Jou. of Real-Time Ima. Proc. 11 (1), pp. 93-109 (2016)

25. Kotkunde, N., Krishna, G., Shenoy, S.K., Gupta, A.K., Singh, S.K. International Journal of Material Forming, 10 (2), pp. 255-266 (2017)

26. Govardhan, D., Kumar, A.C.S., Murti, K.G.K., Madhusudhan Reddy, G. Materials and Design, 36, pp. 206-214. (2012)

27. Kumar, P., Singhal, A., Mehta, S., Mittal, A. Journal of Real-Time Image Processing, 11 (1), pp. 93-109. (2016)

28. Raghunadha Reddy, T., Vishnu Vardhan, B., Vijayapal Reddy, P. International Journal of Applied Engineering Research, 11 (5), pp. 3092-3102 (2016)

29. Hussaini, S.M., Krishna, G., Gupta, A.K., Singh, S.K. Journal of Manufacturing Processes, 18, pp. 151-158 (2015)

30. Kotkunde, N., Krishna, G., Shenoy, S.K., Gupta, A.K., Singh, S.K, Int. Jou. of Mat. Form, 10 (2), pp. 255-266., (2017)

31. Govardhan, D., Kumar, A.C.S., Murti, K.G.K., Madhusudhan Reddy, G, Mate. and Des. 36, pp. 206-214 (2012)

32. Pavani, K.V., Sunil Kumar, N., Sangameswaran, B.B, Polish Jour. of M.B, 61 (1), pp. 61-63(2012) 